\title{
Android-Based Mobile Learning Resource for Chemistry Students in Comprehending the Concept of Redox Reactions
}

\author{
https://doi.org/10.3991/ijim.v16i03.24133 \\ Muhammad Nazar ${ }^{(凶)}$, Rusman, Kana Puspita, Husnul Yaqin \\ Faculty of Education and Teacher Training, Universitas Syiah Kuala, Banda Aceh, Indonesia \\ mnazar@unsyiah.ac.id
}

\begin{abstract}
This study aimed to develop an Android learning media on the concept of redox and evaluate the quality and usability of the app. The approach used in this research was a quantitative deployed as development research, while the model used was the Hannafin and Peck (1988). The data of this study were collected from the process of development, expert evaluations (expert reviews), and small group evaluation. 20 students of the chemistry education study program at a university in Indonesia volunteered to use and evaluate the app, Data were collected by using questionnaires. The results indicate that the quality of the application obtained from expert review was $94.7 \%$. Furthermore, the small group evaluation shows that the usability of RedoksPro version 1.1 scored 86.7. The Android-based learning media of redox concept (RedoksPro application version 1.1) could be utilized as a mobile learning resource in learning the specific concept of reduction and oxydation reactions.
\end{abstract}

Keywords — android app, redox reactions, chemistry, learning media

\section{Introduction}

Chemistry topics usually consists of specific terms and its complexity has promoted difficulties for students to fully comprehend the entire concepts of chemistry, and the redox concept is included. Some problems encountered by students in mastering the concept of redox are contributed by large number of definitions and terms used by both teachers and chemistry textbooks. In addition, numerous rules in determining the oxydation states of subtances in molecules would be chalengging for students. Therefore, a unique strategy and alternative learning resources are crucial and demanded in modern class rooms.

To better comprehending the concept of redox, students need to master prerequisite concepts such as chemical subtances, molecules, chemical reactions, balanced chemical reactions, and the concept of oxidation states of many substances. Those concepts are somehow abstract and thus quite challenging for students. Therefore, technological approach like mobile learning is very promising to help them learn better. By using a mobile device for learning, students not only engaged to the learning matters due to their interest of using gadget but they also capable of maintaining the time and place 
to learn since the mobile learning is flexible and handy. Mobile learning by definition is the learning process that takes place anywhere and anytime through utilization of mobile devices like smartphone, tablet and so forth [1]. Mobile learning is considered by many teachers and researchers to be an effective and efficient way to learn a complexed concept because it is sustainable, mobile and cheap [2].

Android apps are very powerful and sustainable as learning media, it is flexible, economic, and in a top that, the android app can be repeatedly and simultanously used by students in learning activities [3]. Frequent learning and repeat use of learning resources could enhance students' academic performance [4]. Furthermore, Android platform provides opportunity for teachers to combine all types of media i.e visual, audio, text, and evaluation tools that activate multiple recognitions of students [5]. They could practically activate most of their five senses at the same time, which is very useful for students in mastering challenging course like chemistry.

Despite of great availability of android app about chemistry on the Google Play developed by community and programmers, only several apps were developed for academic purposes and went through a Research and Development process. Most apps were only built for commercial use and contained ads, some apps were not properly designed for learning, thus didn't meet the criteria of proper learning resources and most of them were developed without need analysis. Moreover, most developers and researchers are more interested in making app for popular topics in Chemistry like 3D molecule, periodic table, atom and molecule, and chemistry animation. But it is barely hard to find apps for specific concepts such as redox, colloids, and chemical reactions. But some works related to chemistry has been conducted. For example, ChemDic [6] a chemistry dictionary app, ARChem [4], an Augmented Reality app, and AVALIMA [5] an Android app designed to enhance chemical literacy among students.

In this work, we developed a learning module in the topic of redox reaction containing important components including content knowledge, tutorial, and quiz. The app was designed to be useful for students in independent learning beyond the class room. Independent learning skills is very important for students in this situation because after Covid-19 outbreak about a year ago, most of the primary educational institutions and higher education considered to conduct the online learning process. Students are required to mostly use the online learning resources to avoid physical contact. Therefore, integrated app like RedoksPro could benefitial for both university and high school students in mastering the specific concept of redox reactions. The research questions for this research therefore are: 1) How valid is the the RedoksPro app in terms of learning media and content knowledge, and 2) How ease the RedoksPro app to be utilised as learning resource in supporting the distance learning?.

\section{Research method}

\subsection{Development framework}

The app was designed by $\mathrm{R} \& \mathrm{D}$ reseach methodology by adopting the Hannafin \& Peck model (1988). R\&D is defined as a research method used to produce a specific product integrated with evaluation or assessment of the product prior to mass production. Development procedures as refers to the Model suggested by Hannafin \& Peck (1988) 
consisted of three stages: the need analysis phase, the design phase, and the development phase [7]. The development model of Hannafin \& Peck integrates the development of a product and evaluation processes involving the three levels simultanously. The development design utilized for this work is depicted by Figure 1.

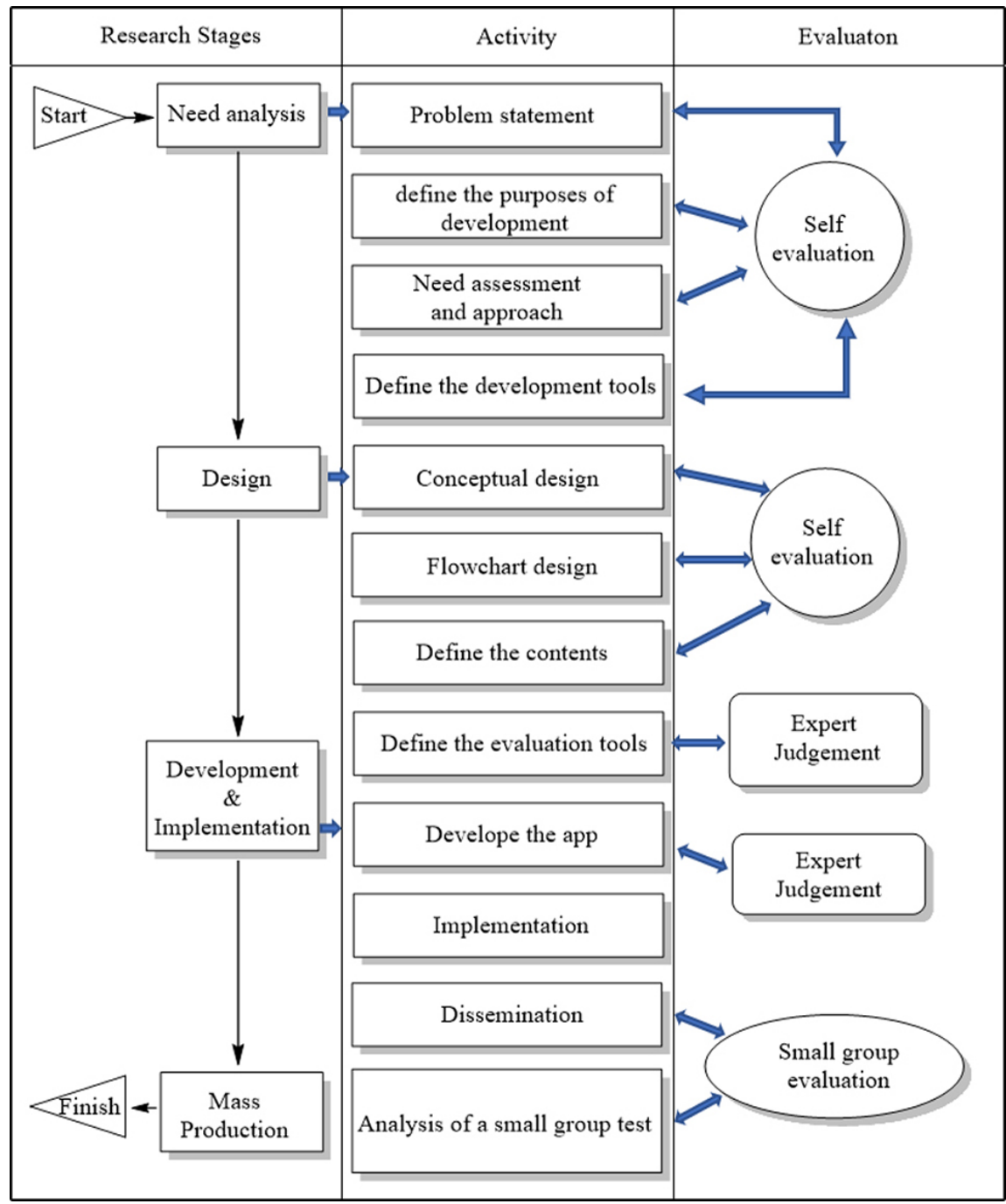

Fig. 1. Development phases of RedoksPro App as modified from the model of Hannafin \& Pack

The system requirement analysis which is the crucial part of development process was initiated and relied on the activity theory [8]. The activity theoretical framework allows developers to analyse the basic criteria of app development based on the activity that prefered by users [9]. The next stage was conceptual design which combined with the body knowledge content and app life circle. These three components were subjected to evaluation as shown by Figure 1. Each stage of the development process undergoes proper evaluation including expert judgement, and small group evaluation. 
The evaluation data was collected by using questionaires i.e validating questionaires and System Usability Scale (SUS) questionaires which was translated from the model developed by Brooke (1996). SUS is a powerful surveying tool frequently and originally used to evaluate the usability of a website and other computer programs [8]. Moreover, SUS questionnaire is among valid and reliable instruments for evaluating a small group testing [10]-[13]. SUS was designed based on Likert scale. Pyae et al. [14] stated that SUS is developed based on a 5 poin Likert scale with qualitative criteria of strongly disagree, disagree, neutral, agree, and strongly agree.

SUS is commonly used to measure the usability of websites but it is also popular among computer practitioners as a measuring tool of any systems and applications of digital products such as computer software, and mobile apps [11]. Even though other templates of questionnaire are also available to measure usability [15], SUS is still preferred because of the following reasions 1) SUS is quick, and the template is readily available, thus rephrasing is not required; 2) SUS is inexpensive because the questionnaire can be administered easily without much effort, and most importantly 3) SUS is simple but reliable [16]. Thausands of studies involving SUS in computer and mobile system evaluation have been reported. Although the a ten-item scale of SUS looks simple, it has been continously validated and tested by many researchers and practiotioners. The SUS questionnaire is given by Figure 2 .

\section{System Usability Scale}

For each of the following statements, please mark one box that best describes your reactions to Android App today.

1. I think that I would like to use Android App frequently.
2. I found Android App unnecessarily complex.
3. I thought Android App was easy to use.
4. I think that I would need the support of a technical person to be able to use
5. Indroid App.
6. I found the various fundions in Android App were well integrated.
7. I would imagine that most people would learn to use Android App very
8. I found Android App very cumbersome (awhward) to use.
9. I felt very confident using Android App.
10. I needed to learn a lot of things before I could get going with Android App.

Comments (optional):

Fig. 2. The SUS questionnaire sample generated online from: https://www.usabilitest.com/sus-pdf-generator 
SUS is not diagnostic thus unable to detect the specific problem with a program or product, but it can assess whether the product is accaptable by users or not. The questionnaire of SUS contains ten statements devided to five odd statements (positive) and five even statemets (negative). The users will have ranked every single question (See Figure 2) from 1 to 5 according to the level of agreement. To calculate the result of SUS, the following rules have to be considered:

- Subtracting 1 from the score for each of the odd numbered questions $(1,3,5,7$, and 9)

- Subtracting the value from 5 for every even numbered questions $(2,4,6,8$, and 10)

- Adding up the total score, and then multiply the obtaining value by 2.5 . [17]

A small group students $(\mathrm{N}=20)$ who enrolled in the Class of General Chemistry at the Department of Chemistry Education, Syiah Kuala University volunteered in the evaluation of the app. While for validating the app, four lecturers were involved in testing the app and commenting on software design, contents, language, and visual communications. The validation questionnaire was developed as a 10 question instruments with four sub-indicators as mentioned above including software desain (3 items), content knowledge (4 items), language (1 item), and visual communication (2 items).

\subsection{Development tools}

The app was developed using Android studio, the material and components like buttons and figures were designed and created using image processing software for Microsoft Windows.

\subsection{Limitations of research}

The app was developed for specific purpose both scope and user target, so the following limitations of the research should be taken into account:

- The app emphasizes only on the topic of redox reaction.

- The language used was Indonesian (Bahasa) except for splash screen and couple buttons in about app info.

- Most components of the app are text form whitout any multimedia features.

- The number of respondent who participated in the testing phase were 20, thus the result of the testing process cannot be generalized, and further testing with wider audience would be required.

\section{$3 \quad$ Results and discussions}

\subsection{Need analysis}

The education practitioners are coming up with new techniques to impart knowledge every day. Some of teachers or lecturers have tried to expose students to activities that engage them in learning through innovative ways. The ICT phenomenon has driven the learning process through revolutionary phase and rapid transformation from traditional learning environment to modern based learning where information and communication 
technology involved more significantly in learning environment. Therefore, assessing the need of specific software for special purpose like chemistry is then become crucial. In this work, Activity theory of need analysis were employed to begin building the app.

The activity theory is a conceptual framefork relies on the activity which was originally introduced by the Russian psychologist Aleksei Leontiev. Even though the theory was developed in the field of psychology, it has been widely used interdisciplinarily, not only in psychology, but also in diverse fields, including organizational learning, education, and cultural studies. In addition, the activity theory has been popular as the theoretical landscape of Human-Computer Interaction (HCI) since 1990. Figure 3 would be helpful to illustrate the implementation of activity theory on the development of RedoksPro app as suggested by Uden, 2007 [18].

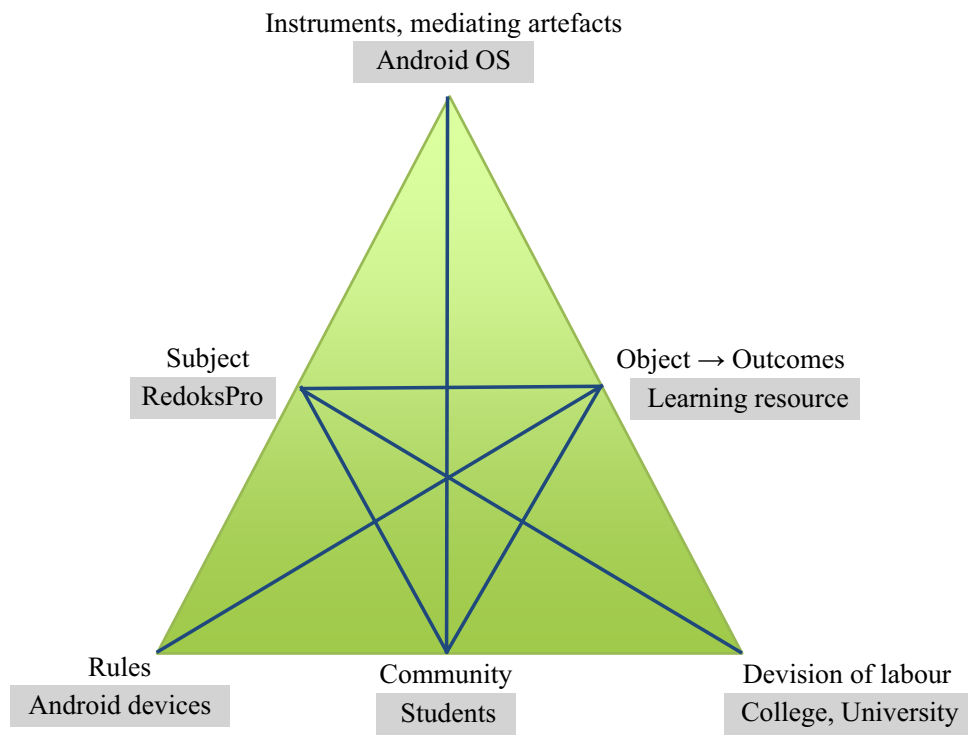

Fig. 3. Structure of activity

Nik Ahmad and Hafizuddeen [19] suggested the benefit of using activity theory in developing android app is that the researchers are able to observe interaction between the subjects, community and environment. The Activity theory was not implemented only at the begining of the development but it integrated in the entire process of development explicitely.

\subsection{App design and development}

Conceptual design of the app was carried out by integrating the cognitive learning theory (CLT), deductive learning approach with the text as learning intermediaries in prototyping the app. The CLT is a learning theory that explore how human brain work while learning process occurred. How the informations are processed by students is 
important and crucial to be addressed to understand what kind of learning media could positively elevate the student ability in acquiring the concept they learn.

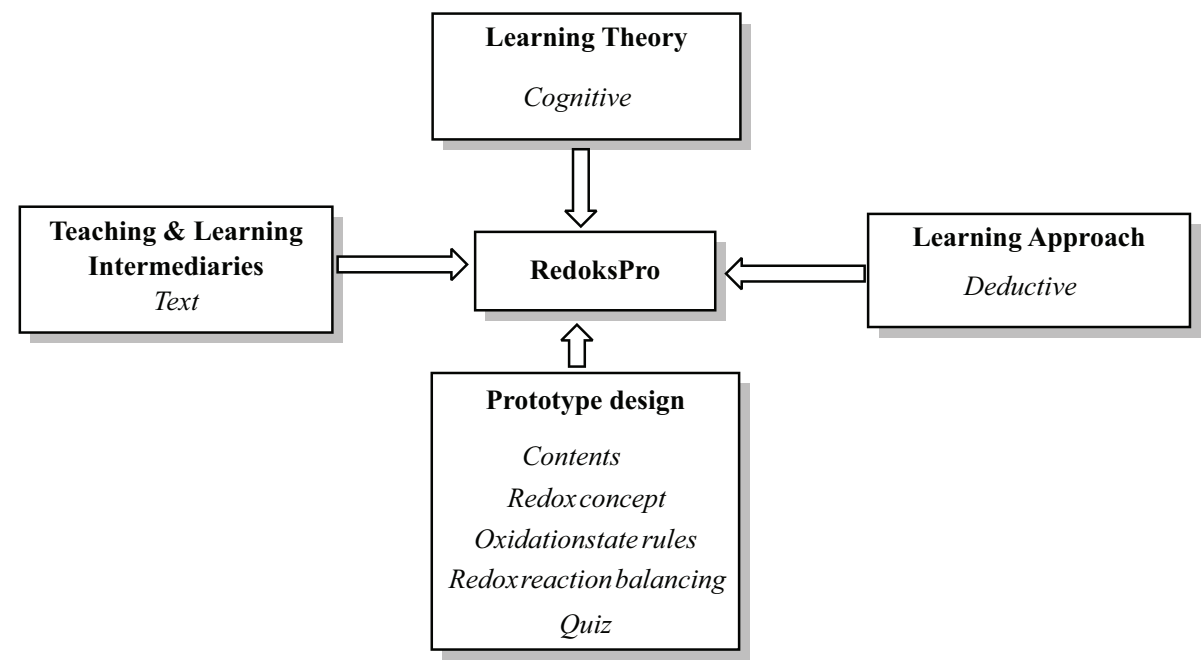

Fig. 4. Conceptual framework for developing RedoksPro

Figure 4 depicts the conceptual frameworks used in developing the app of RedoksPro. Text is the classical yet robust media of learning that cannot be avoided by learners in the past or future. Despite of rapid and dynamic progress in deploying video and animation for learning in this era, texts still play enermous role in delivering learning contents and cannot completely be neglected. Numerous scientific articles, books, and online resources are presented as texts. Therefore, utilizing texts in a learning media is completely relevant for current time and in the future.

Students are required to be able to deduct and decide the appropriate stages taken in balancing the complexed redox reactions. Fail to fulfil several parts in balancing redox reactions resulted in incorrect or inbalanced chemical reactions. Therefore, the main focus of developing this app was to overcome students' inability in balancing a redox reaction. However, it is also important to refresh students' mind by introducing the concept of reduction and oxydation reactions as prerequisite concept. The full activities of the app is illustrated by the flowchart. 


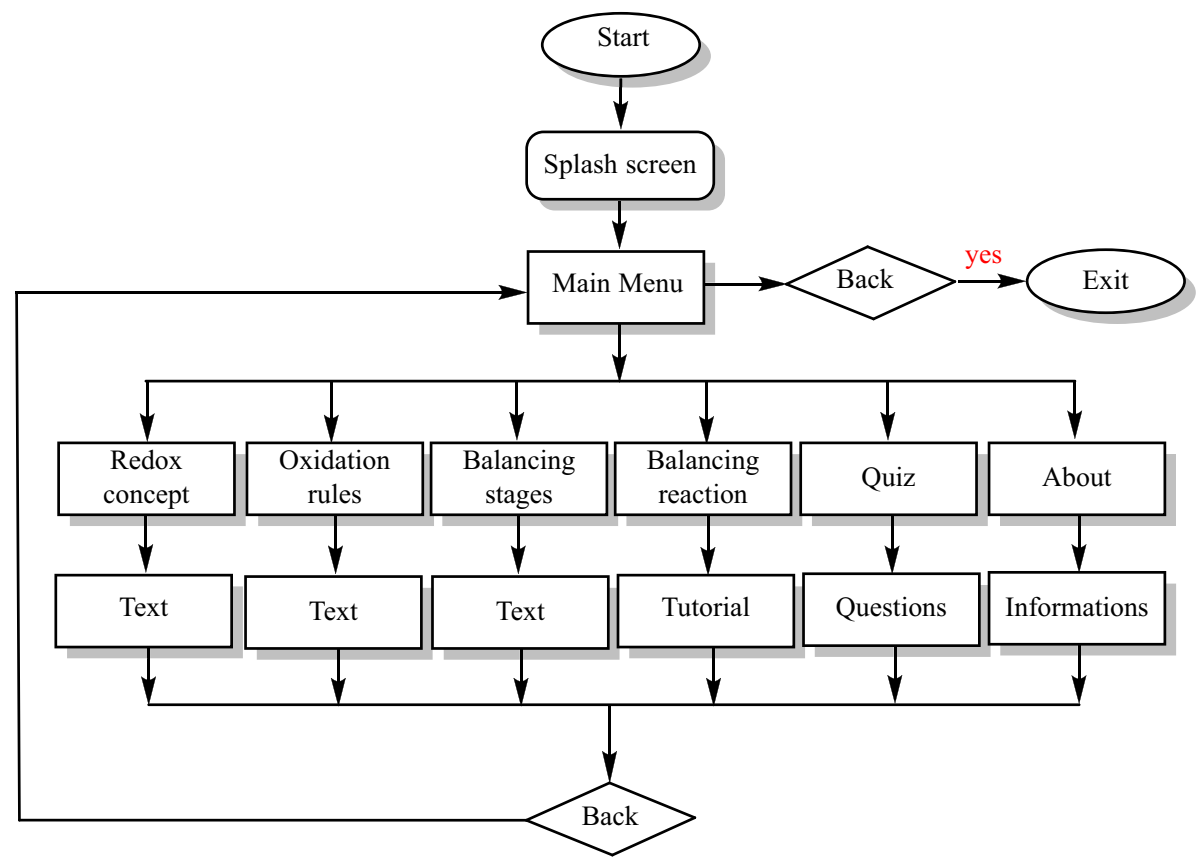

Fig. 5. Application flow chart

Figure 5 show the flow chart of the app when being operated on the Android smartphone. The main activities of the app consisted of four sub-subject matters including redox concept, oxidation state rules, stages for balancing redox reactions, and an example for redox reaction balancing. Furthermore, a ten question quiz and further information about the app also available. The UI flow of the app determine how easy the app is to be used by the users, and every developer should take it in to account that the user friendly app is important [20]. Therefore, conducting a research exploring about what users say, think and feel toward a desired app become very essential. Figure 6 shows some screen captures of the app from different activities. 


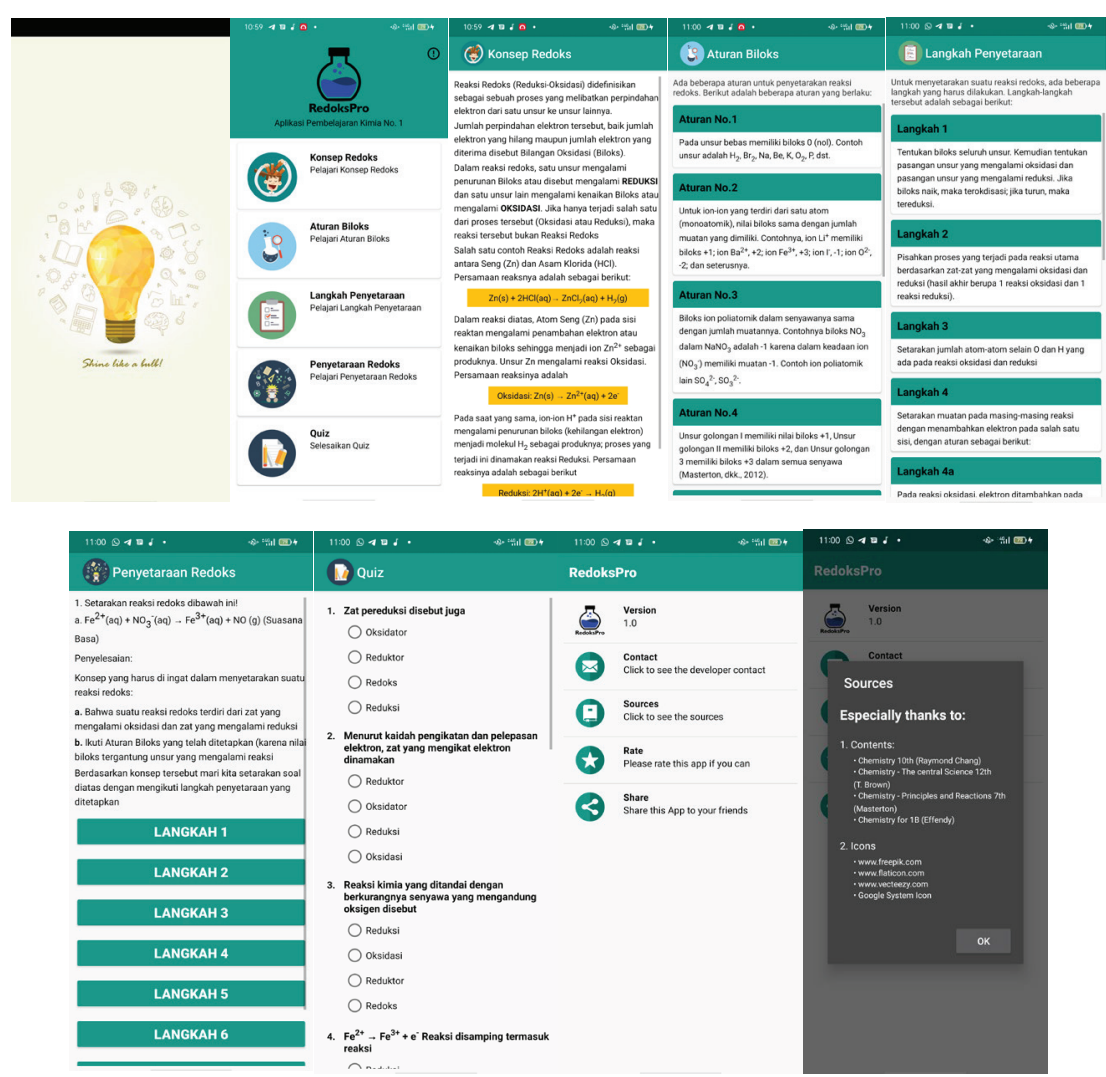

Fig. 6. Screen captures of the RedoksPro app showing some important app activities including a quiz

Figure 6 illustrates screen shots of the developed app showing all features of the app from splash screen, primary contents, quiz, and detailed informations about the app include the sources of contents and icons used in developing the app. The main screen displays five main menus allowing users to start exploring the materials, doing step by step exercise or quiz. Each screen of sub-menus can be scrolled down to finish reading. Furthermore, we also include ten questions in the quiz section.

\subsection{App evaluation}

In order to evaluate the app, two different questionnaires were used. The first qustionnaire was intended to validate the app by assessing several aspects including design, content of knowledge, language, and visual appearance of the app. After prototyping, 
the app was delivered to four experienced evaluators. The second instrument was a System Usability Scale consisting 10 statements (See Figure 2) which handed out to 20 students.

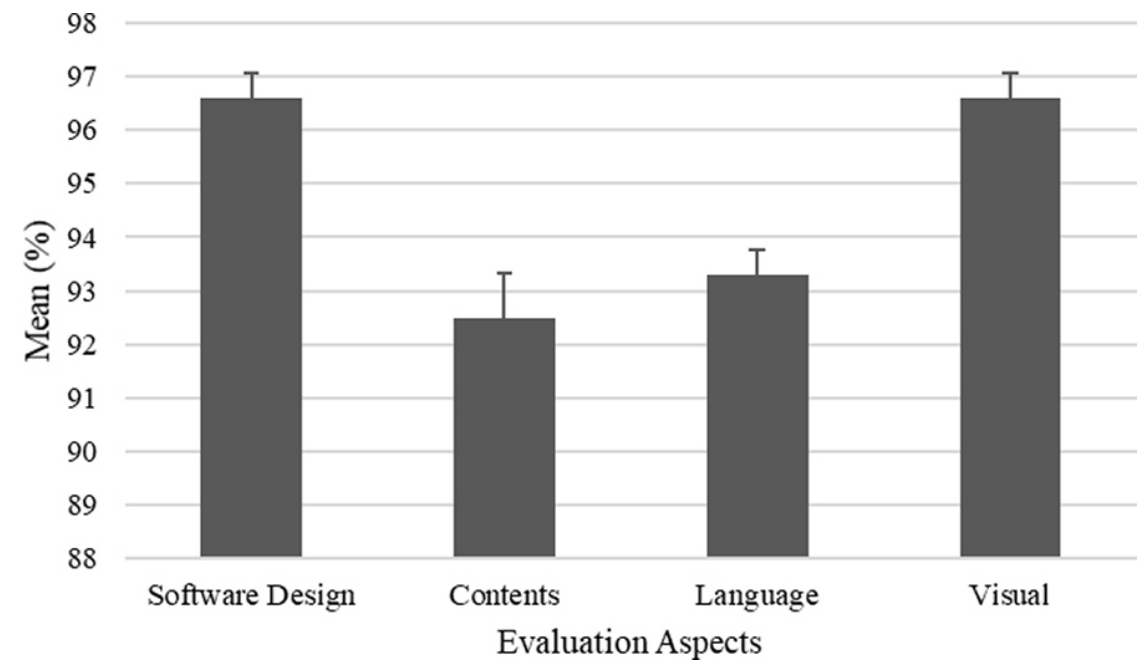

Fig. 7. Expert judgement of the RedoksPro app (\% with SE)

Figure 7 revealed that the expert judgment ensure the validity of the app in four different aspects. Software design and visual appearance of the app scored better than the aspect of contents and language, but all aspects scored greater than $92 \%$. The aspect of software design assessed in this work include app effectivity, usability and maintainance. While the visual aspect include text readability, colors choosing and buttons allocation. In the aspect of content, the following indicators were evaluated; conceptual lucidity, conformity of the concept with chemistry, and the relevance of the quiz to the content. All aspects of app contents shows lowest score comparing to other aspects as depicted in Figure 7. However, the overall score of evaluating aspects reached 94.7 percent.

Validity of a product in a research mindset is some how very important to ensure that the users would get what they desire and expect. By doing the early evaluation through Expert Judgment, a developer will be able to inspect both the advantages and disadvantages of the app which is allowing a developer to make a revision prior to final production. Expert Judgment is a common technique used to evaluate a product or an instrument in which judgment is provided according to specific criteria involving practitioners, expertise or professional in particular field [21]. 


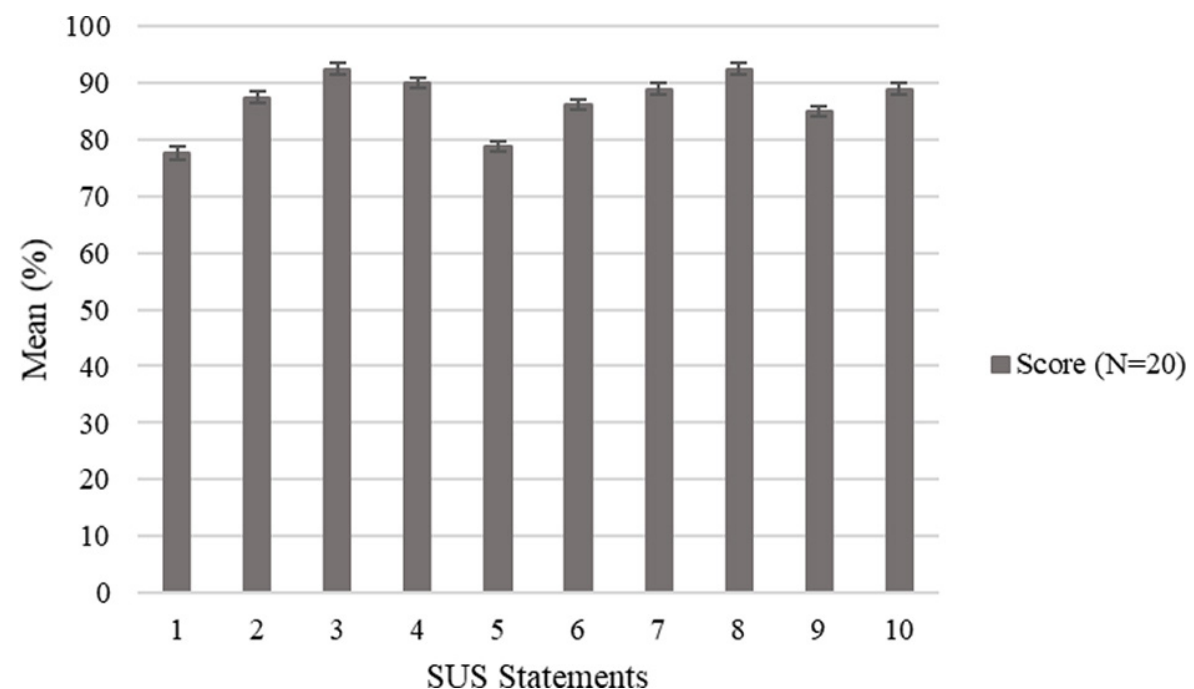

Fig. 8. SUS score obtained from a small group evaluation (\% with SE)

Figure 8 shows usability score of the app based on a small group evaluation $(\mathrm{N}=20)$. The score displayed as mean for each statement. The total score of SUS was found to be $86.77 \%$ which is catagorised as excellent adjective rating [22]. Similar apps developed by [23] for elementary students shows less practical with a qualitative grade of "Good" due to monotonous contents without any added features like a quiz. Another similar app of e-module about nerve system developed by [24] have also shown "Eligible" criteria with an IT-expert judgement score of $80 \%$ but was much lower when compared to the app developed in this work (94.7\%) as illustrated in Figure 7.

As stated earlier, this app was developed based on the activity theory as depicted in Figure 3. The initiatial stage of need analysis results (based on literature search) indicate that most of students own android smartphones [2], [25], [26]. Furthermore, recent studies also show that most students at college levels spend more time with their gadgets both during school time or off the campus [27]. Therefore, utilizing Android app for learning purposes is in a great need for nowadays situation.

\section{Conclusion}

In this work, we developed an easy to use mobile app based on Android platform for the particular topic of reduction and oxydation reaction balancing to help students at primary level. The app was validated by Expert Judgment prior to the implementation, the validation score was $94.7 \%$. Moreover, the usability was at greatly acceptable score of $84 \%$. However, we suggest a further testing in the real class room at wider audience for better result. 


\section{$5 \quad$ References}

[1] M. Lane and A. Stagg, "Australasian Journal of Information Systems Volume 18 Number1 2013,” Australas. J. Inf. Syst., vol. 18, no. 3, pp. 53-74, 2014. https://doi.org/10.3127/ajis. v18i3.876

[2] K. Machmud, "The Smartphone Use in Indonesian Schools: The High School Students' Perspectives," J. Arts Humanit., vol. 7, no. 3, p. 33, 2018. https://doi.org/10.18533/journal. v7i3.1354

[3] B. Haßler, L. Major, and S. Hennessy, "Tablet Use in Schools: A Critical Review of the Evidence for Learning Outcomes," J. Comput. Assist. Learn., vol. 32, no. 2, pp. 139-156, 2016. https://doi.org/10.1111/jcal.12123

[4] C. Dziuban, C. R. Graham, P. D. Moskal, A. Norberg, and N. Sicilia, "Blended Learning: The New Normal and Emerging Technologies," Int. J. Educ. Technol. High. Educ., vol. 15, no. 1, pp. 1-16, 2018. https://doi.org/10.1186/s41239-017-0087-5

[5] P. S. Putra, N. B. Asi, M. E. Anggraeni, and Karelius, "Development of Android-Based Chemistry Learning Media for Experimenting," J. Phys. Conf. Ser., vol. 1422, no. 1, 2020. https://doi.org/10.1088/1742-6596/1422/1/012037

[6] M. Nazar and Z. Zulfadli, "Usability Testing of Chemistry Dictionary (ChemDic) Developed on Android Studio," in Proceedings-2017 International Conference on Electrical Engineering and Informatics: Advancing Knowledge, Research, and Technology for Humanity, ICELTICs, pp. 221-225, 2017. https://doi.org/10.1109/ICELTICS.2017.8253265

[7] Mawardi, H. Mudjiman, S. Anitah, and Asrowi, "The Model of Instructional Design Based on Self-Regulated Learning using Modular Object Oriented Dynamic Learning Environment (MOODLE)," J. Educ. Pract., vol. 5, no. 22, pp. 131-140, 2014.

[8] K. S. A. B, T. M. Prajwala, and K. Chandrasekaran, "Activity Theory Based Approach for Requirements Analysis of Android Applications," in Activity Theory Based Approach for Requirements Analysis, U. L., L. W., and I. Ting, Eds. Springer International Publishing, 2017, pp. 3-15. https://doi.org/10.1007/978-3-319-62698-7 1

[9] L. Uden, P. Valderas, and O. Pastor, "An Activity-Theory-Based Model to Analyse Web Application Requirements," Inf. Res., vol. 13, no. 2, 2008.

[10] A. Madan and S. K. Dubey, "Usability Evaluation Methods: a Literature Review," Int. J. Eng. Sci. Technol., vol. 4, no. 02, pp. 590-599, 2012.

[11] A. Bangor, P. T. Kortum, and J. T. Miller, "An Empirical Evaluation of the System Usability Scale,” Int. J. Hum. Comput. Interact., vol. 24, no. 6, pp. 574-594, 2008. https://doi. org $/ 10.1080 / 10447310802205776$

[12] K. Kalimullah and D. Sushmitha, "Influence of Design Elements in Mobile Applications on User Experience of Elderly People," Procedia Comput. Sci., vol. 113, pp. 352-359, 2017. https://doi.org/10.1016/j.procs.2017.08.344

[13] A. I. Martins, A. F. Rosa, A. Queirós, A. Silva, and N. P. Rocha, "European Portuguese Validation of the System Usability Scale (SUS)," Procedia Comput. Sci., vol. 67, pp. 293-300, 2015. https://doi.org/10.1016/j.procs.2015.09.273

[14] A. Pyae, T. Liukkonen, T. Saarenpää, M. Luimula, P. Granholm, and J. Smed, "When Japanese Elderly People Play a Finnish Physical Exercise Game: A Usability Study," J. Usability Stud., vol. 11, no. 4, pp. 131-152, 2016.

[15] D. Rubin and J. Chisnell, Handbook of Usability Testing [Electronic Resource]: How to Plan, Design, and Conduct Effective Tests (2nd Ed.). 2008.

[16] C. Peres, T. Pham, and R. Phillips, "Validation of the System Usability Scale (SUS): SUS in the Wild," in Proceedings of the Human Factors and Ergonomics Society 57th Annual Meeting, 2013, no. 1, pp. 192-196. https://doi.org/10.1177/1541931213571043 
[17] T. Nathan, How To Use The System Usability Scale (SUS) To Evaluate The Usability Of Your Website, 2012. [Online]. Available: https://usabilitygeek.com/how-to-use-the-systemusability-scale-sus-to-evaluate-the-usability-of-your-website/. [Accessed: 21-May-2021].

[18] L. Uden, “Activity Theory for Designing Mobile Learning," Int. J. Mob. Learn. Organ., vol. 1, no. 1, pp. 81-102, 2007. https://doi.org/10.1504/IJMLO.2007.011190

[19] N. A. Nik Ahmad, N. I. Akhbariee, and M. Hafizuddeen, "Requirements Analysis of Android Application using Activity Theory: A Case Study," 2013 Int. Conf. Inf. Commun. Technol. ICoICT 2013, pp. 145-149, 2013. https://doi.org/10.1109/ICoICT.2013.6574563

[20] S. Lauesen and M. P. Musgrove, "Heuristic Evaluation of User Interfaces versus Usability Testing," in User Interface Design: A Software Engineering Perspective, 2005.

[21] Project Management Institute, A Guide to the Project Management Body of Knowledge, 5th ed., vol. 34, no. 03. Pennsylvania: Project Management Institute, Inc., 1996. https://doi. org/10.5860/CHOICE.34-1636

[22] A. Bangor, P. Kortum, and J. Miller, "Determining What Individual SUS Scores Mean: Adding an Adjective Rating Scale," J. Usability Stud., vol. 4, no. 3, pp. 114-123, 2009.

[23] N. Mahardika, B. S. Degeng, I. Nyoman, and N. C. Sitompul, "E-Module Application Development Based on Android in Thematic Learning for 3rd Grade Elementary School," Akademika, vol. 10, no. 1, pp. 13-24, 2021. https://doi.org/10.34005/akademika.v10i01.1322

[24] S. Alfaris, B. Lian, and Mulyadi, "The Development of Android Based Digital Module Materials for Human Nerve Systems in SMA Negeri 1 Cengal, Ogan Komering District Ilir," Proc. Int. Conf. Educ. Univ. PGRI Palembang (INCoEPP 2021), vol. 565, no. INCoEPP, pp. 228-232, 2021. https://doi.org/10.2991/assehr.k.210716.041

[25] S. Baert et al., "Smartphone Use and Academic Performance: Correlation or Causal Relationship?," KYKLOS, vol. 73, no. In Press, pp. 1-25, 2019. https://doi.org/10.1111/kykl.12214

[26] N. Othman, M. Khairuz, S. Bin, T. Soe, and S. Jamaludin, "Practique Clinique et Investigation The Impact of Electronic Gadget Uses with Academic Performance among Secondary School Students," Prac Clin Invest., vol. 2, no. 2, pp. 56-60, 2020.

[27] M. Nazar, R. Muliana, and L. Hanum, "Smartphone Use and its Effects on the Student Final Grade (A Case Study in the Environmental Chemistry Class)," in Proceeding of the 2nd URICES, 2018, pp. 978-979.

\section{Authors}

Muhammad Nazar is a member of Indonesian Chemical Sciety (HKI), a lecturer at the department of chemical education, Faculty of Education and Teacher Training, Universitas Syiah Kuala. He is interested in the research of android development, learning media, chemistry, and biodiesel.

Rusman is an associate professor at the Department of Chemical Education, Faculty of Education and Teacher Training, Universitas Syiah Kuala.

Kana Puspita is a junior lecturer at the department of Chemistry Education, Faculty of Education and Teacher Training, Universitas Syiah Kuala.

Husnul Yaqin is an undergraduate student at the department of chemical education, Faculty of Education and Teacher Training, Universitas Syiah Kuala.

Article submitted 2021-05-20. Resubmitted 2021-09-21. Final acceptance 2021-11-30. Final version published as submitted by the authors. 